\title{
Novos cenários de participação política: análise das estratégias de comunicação dos grupos de pressão (lobbies)'
}

\author{
New political participation scenarios: \\ analysis of the communicetion strategies \\ of the pressure groups (lobbies)
}

Nuevos escenarios de participación políticea: análisis de las estrategias de comunicación de los grupos de presión (lobbies)

\section{Antonio Castillo Esparcia}

- Doutor em Jornalismo pela Universidad Autònoma de Barcelona (UAB).

- Professor da Facultad de Comunicación da Universidad de Málaga (UMA)

- Diretor do Programa de Mestrado de Gestão Estratégica e Inovação em Comunicação da UMA

- Diretor do Programa de Doutorado de Gestão Estratégica em Comunicação da UMA

- Autor de seis livros sobre comunicação e de grande número de artigos em revistas científicas

• acastilloe@uma.es

1 Texto traduzido do original espanhol por Pamela Pereira da Silva, estudante da Universidade Luterana do Brasil (Ulbra), com revisão técnica de Andreia Silveira Athaydes, docente da Ulbra. 
Este artigo tem dois objetivos: eliminar os estereótipos sobre o que é o lobby e explicar quais são as suas técnicas e estratégias. A partir disso, explicar o que é um lobista e as características que ele deve ter, além de citar as atividades que uma campanha de lobby pode promover e como aplicá-las corretamente. O lobby é muito pouco conhecido. O presente artigo enquadra o lobbying como umas das técnicas de relações públicas, pois é basicamente uma forma de comunicação entre as organizações e os poderes públicos. Portanto, essa moderna atividade está longe de velhos conceitos que a associavam a chantagem e a suborno, já que na atualidade concentra sua atuação em ações dirigidas a toda a população, com a intenção de influenciar os governantes.

PALAVRAS-CHAVE: COMUNICAÇÃO POLÍTICA • LOBBY • MEIOS DE COMUNICAÇÃO

\section{Abstract}

This article pursues two objectives: to eliminate stereotypes on what lobbying is and to describe its techniques and strategies. From there, explain who a lobbyist is and what are the characteristics that he should bear, as well as affirm the activities that a lobbying campaign can use and how to apply them correctly. Lobbying is still a little-known activity. The text classifies lobbying as one of the techniques that characterize public relations, since it is basically an act of communication between organizations and public powers. Thus, this modern activity is far from the old concepts that associated it with blackmail and bribery, since presently it focuses its activity on the actions aimed at the population as a whole, with the intention of influencing the government.

KEYWORDS: POLITICAL COMMUNICATION • LOBBY • MASS MEDIA

\section{Resumen}

Este artículo tiene dos objetivos: eliminar los estereotipos sobre qué es el lobby y explicar cuáles son sus técnicas y estrategias. A partir de ahí, explicar qué es un lobista y las características que debe tener, además de citar las actividades que una campaña de lobby puede promover y cómo aplicarlas correctamente. El lobby es muy poco conocido. El presente artículo aborda el lobbying como una de las técnicas de relaciones públicas, pues es básicamente una forma de comunicación entre las organizaciones y los poderes públicos. Por lo tanto, esta moderna actividad está lejos de los viejos conceptos que la asociaban al chantaje y al soborno, ya que, en la actualidad, concentra su actuación en acciones dirigidas a toda la población, con la intención de influir sobre los gobernantes.

PALABRAS CLAVE: COMUNICACIÓN POLÍTICA • LOBBY • MEDIOS DE COMUNICACIÓN 
0 estudo das organizações sociais atuantes no sistema político não foi, até algumas décadas atrás, um aspecto fundamental e central de pesquisas realizadas nas áreas de ciência política e de comunicação. Esta última estava mais interessada nos aspectos formais e institucionais do que a vertente dinâmica e informal da atividade política. Durante muito tempo, a atividade de grupos de pressão não foi considerada um fenômeno geral das organizações corporativas, mas uma característica do sistema político norte-americano. Situação que levou ao atraso, até a década de 1950, do surgimento na Europa dos primeiros estudos desses atores do sistema político ${ }^{1}$.

Em qualquer organização social, grupos de pressão aparecem como um elemento indissociável da estrutura política, com uma representação no processo, longo e complexo, da formação de decisões, tanto integrando as demandas quanto definindo a hierarquia, a ordem das propostas ou solicitações que provavelmente serão abordados na discussão política. O tema dos grupos e seu impacto social, político e econômico levou os especialistas que estudam a dinâmica política a fornecer descrições e condições diferentes para as demandas dirigidas ao exterior por esses grupos ${ }^{2}$. Quando essas ações se desenvolvem de forma endógena (ad intra), os autores, geralmente, adotam o termo grupo de interesse. Enquanto isso, as ações e atuações exógenas do grupo que visem ao sistema político, recebem usualmente o termo grupo de pressão. Além disso, pode-se utilizar de forma recorrente a expressão lobby,, que está associada, principalmente, a um grupo de pressão, mas, em um sentido próprio e restrito, refere-se às empresas especializadas na função de pressionar em nome de terceiros.

Grupos de interesse normalmente é um conceito com conotações econômicas. Mas para os pesquisadores de psicologia social e sociologia ele se desvincula das contribuições financeiras para participar de elementos próprios das estruturas e das estratificações sociais. Os conceitos associados a essas disciplinas psicossociais citam o impacto da atitude, do comportamento, da ideologia, da opinião como inerente ao termo interesse $e^{3}$. Também se apresenta associada à atuação dos grupos de pressão a noção de interesse parcial, em por oposição aos interesses gerais ${ }^{4}$. Dion $(1967$, p. 126) assegura que o termo pressure groups apareceu pela primeira vez, na literatura científica, no título de livro publicado em 1928 por Peter Odegard sobre a Anti-Saloon League.

1 Os primeiros estudiosos da incidência política desses tipos de associações foram: J. D. Stewart (1958); S. E. Finer (1958); A. Potter (1961); J. Meynaud (1958); e J. H. Kaiser (1956).

2 Jean Meynaud e Jean Meyriat (1959, p. 229-246) realizaram um levantamento bibliográfico sobre as publicações referentes aos grupos de pressão até o ano 1959, em diferentes países europeus (Alemanha, Bélgica, Finlândia, França, Grã-Bretanha, Itália, Noruega, Países Baixos, Suécia e Suíça).

3 Para aprofundar-se sobre esses elementos, pode-se recorrer à análise de Dion (1982, p. 58-108).

4 Glendon Schubert (1960) pode esclarecer um pouco a dificuldade de apreensão, a complexidade e o problema para a formulação empírica do interesse geral. Existe uma aproximação espanhola no livro de Camps e Giner (1992). 
O termo lobby, ainda segundo Dion (1967, p. 126), apareceu antes do conceito de pressure groups,. Durante muito tempo, ele designou os corredores da Câmara Baixa da Grã-Bretanha. Posteriormente, passou a aplicar-se às conversações realizadas nos corredores e, por volta de 1830 se estendeu ao conjunto de grupos que pretendiam influenciar os parlamentares. Outros autores, como Farnel (1994, p. 19), atribuem a expressão ao general Grant, presidente dos Estados Unidos, o qual, após um incêndio que destruíra a Casa Branca, se lamentava da grande afluência de pessoas que pululavam no andar térreo do hotel onde ele residia temporariamente. Para H. L. Mencken (Dion, 1967, p. 127), autor de um dicionário da língua norte-americana, os termos lobby-agent e lobby foram utilizados pela primeira vez nos Estados Unidos em 1829, ano em que Andrew Jackson conquistou a presidência do país. Apesar disso, na opinião de Mencken, a palavra lobbyist não foi utilizada de forma corrente em Washington até 1837.

Podem-se definir os lobistas como agentes ou representantes profissionais das associações e dos grupos que se dedicam a intervir, principalmente, sobre os governantes ou sobre aquelas pessoas designadas para tomar decisões que afetem os interesses grupais. Seu trabalho consiste na mediação que realizam entre seu cliente e o destinatário. Assim, os lobistas disponibilizam seus contatos e conhecimentos para aqueles grupos que não podem ou não querem realizar a influencia de forma direta. A utilização dos lobistas é diretamente proporcional à impossibilidade de exercerem elas próprias empresas as ações de pressão. Assim, Robert H. Salisbury 199, p. 220) afirma que a presença de agentes de lobby em nome de uma empresa está relacionada a seu tamanho e a seu volume de vendas.

Historicamente, o termo lobista tem tido um sentido negativo, em razão da imagem, certamente simplista, de uma pessoa que causa intrigas e atua na sombra, tentando alcançar seus objetivos por meio de chantagem, suborno ou corrupção. No entanto, nos últimos anos, parece que essas conotações pejorativas foram se perdendo ao aparecer a profissão sob um manto de maior dignidade e reconhecimento. Assim, cada vez mais, se procura desenvolver diferentes regras e regulamentos, que permitam certo poder de controle sobre o acesso e as ferramentas desenvolvidas por esses grupos privados.

Ernest e Elisabeth Wittenberg (1989, p. 7) ressaltam essa mudança de percepção mostrando o exemplo de que, nas recepções realizadas pelas embaixadas no passado, quando se perguntava à pessoa sobre sua profissão, ela nunca se definia como lobista, mas sim como especialista em relações legislativas. Atualmente, já existe menos "medo" em alguém se definir e se apresentar como lobista. Concorre para tanto o uso de vários termos que tentam contornar a referência específica ao termo lobby, como as ações de escritórios de advocacia, consultorias de relações públicas e assessorias de comunicação. No entanto, apesar dos progressos, muitos ainda se mostram reticentes às atuações e intervenções dos lobistas. 


\section{CONTEXTO SOCIAL DAS ASSOCIAÇÕES SOCIAIS}

O ponto de partida da análise de grupos na vida social e política vêm da pesquisa realizada por Arthur Bentley ${ }^{5}$,em seu estudo sobre as diferentes manifestações sociais. Assim, cabe citar sua famosa afirmação que reconhece a importância das entidades associativas nas sociedades contemporâneas:

O principal trabalho sobre o estudo de qualquer forma de vida social é a análise dos grupos, que é muito mais do que uma classificação. Quando os grupos são definidos corretamente, está tudo definido. E quando digo tudo, quero dizer todas e cada uma das coisas ( Bentley, 1983, p. 256).

Alexis Tocqueville (1980) disse que era necessário desenvolver e aperfeiçoar a arte de fazer parcerias para se ter uma vida mais igualitária. Ele se destacou como protetor e defensor fervoroso de interesses de grupos de indivíduos contra o poder político. Essa convicção aparece de forma recorrente ao longo das páginas de seu livro La democracia en América Latina, como mostram as seguintes passagens do volume II:

- É claro que cada cidadão, à medida que vai se tornando individualmente mais fraco, mais incapaz de preservar por si próprio a sua liberdade, não aprende a arte de se unir a seus semelhantes para defendê-la, a tirania crescerá inevitavelmente (p. 95-96).

- Assim é que o povo mais democrático da terra é aquele na qual os homens têm aperfeiçoado a arte de perseguir, conjuntamente, o objeto de suas demandas comuns (p. 96).

- Nos povos democráticos, todos os cidadãos são independentes, mas são impotentes, não têm força própria e nenhum deles pode exigir a participação de outras pessoas. Assim não podem fazer nada se não aprendem a ajudarse mutuamente (p. 97).

- Assim como os cidadãos dos Estados Unidos concebem um sentimento ou uma ideia que queiram dar a conhecer ao mundo, se buscam e, quando se encontram, se unem. A partir desse momento, já não são homens isolados, mas sim um poder visível com ações que servem de exemplo, um poder que fala e que é escutado (p. 99).

- Para que os homens conservem sua civilização ou a adquiram, é necessário que a prática associativa se desenvolva e se aperfeiçoe na mesma proporção que aumenta a igualdade nas condições sociais (p. 99).

A diversidade de interesses, para Georges Burdeau (1982, p. 164), se multiplica quanto mais complexa for uma sociedade, situação esta que facilita o surgimento, cada vez mais, de interesses muito específicos e, ao mesmo tempo, contraditórios entre si. A formação dos grupos de indivíduos é o resultado de

5 James Ward (1978, p. 595-603) realizou um estudo exaustivo sobre a obra de Bentley. Além dele, ver também M. 0. Hale (1960, p. 955-961) e R. W. Taylor (1952, p. 214-230).

68 NOVOS CENÁRIOS DE PARTICIPAÇÃO POLÍTICA: ANÁLISE DAS ESTRATÉGIAS DE COMUNICAÇÃO DOS GRUPOS DE PRESSÃO (LOBBIES) - antonio CAstillo esparcia 
dois processos sociais inter-relacionados: o aumento da complexidade social; e a tendência natural de buscar a condição de equilíbrio.

Essa complexidade é o resultado da expansão e especialização que também tem o efeito de uma maior especialização dos grupos para articular melhor as suas próprias necessidades. A dinâmica social e econômica leva a uma progressiva fragmentação da atividade produtiva (em objetos tangíveis e simbólicos). Truman (1968, p. 57) estabelece uma correlação entre complexidade social e especialização, que dão lugar ao incremento de associações:

Com o aumento da especialização e a continua frustração das expectativas geradas devido às rápidas mudanças técnicas, a proliferação de associações é inevitável. De fato, esses acontecimentos são tão seguidos que o ritmo de formação de agrupamentos pode servir como índice da estabilidade de uma sociedade e o número de grupos se pode tomar como índice de estabilidade de complexidade social. As sociedades simples não têm associações (no sentido técnico da palavra) e, à medida que se convertem em mais complexas, isto é, à medida que aumenta o número de grupos altamente diferenciados, desenvolve-se um número maior de associações.

O aumento da complexidade ocorreu no estado e na sociedade. No eEstado, há um aumento quantitativo dos órgãos tradicionais com a criação de instituições de diferente estrutura, como órgãos públicos, institutos autônomos, empresas estatais de direito privado, empresas mistas etc. Na sociedade, a diversificação da estrutura social corporificada em uma especialização social levou a uma proliferação de organizações.

\section{OS GRUPOS DE PRESSÃO NA DINÂMICA POLÍTICA}

A disseminação do sufrágio universal; o surgimento de partidos políticos populares destinados a mobilizar o eleitorado; o surgimento e a organização dos grupos de pressão que representam os interesses de diferentes setores de uma sociedade complexa e tendem a influenciar as decisões públicas; e o desenvolvimento dos meios de comunicação de massa - tudo isso propiciou descobrir outras funções políticas, que não podiam ser apreciadas em sua totalidade durante os séculos XVIII e XIX.

Essas mudanças na percepção sobre a realidade e a dinâmica política levaram Almond e Powell (1972, p. 19) a afirmar a necessidade de outorgar mais complexidade ao modelo tradicional da separação dos poderes (legislativo, executivo e judiciário), acrescentando outras funções, tais como a articulação de interesses, a agregação de interesses e a comunicação política ${ }^{6}$.

6 Sobre a relação entre interesses e sistema político, ver os trabalhos de Cazzola (1984, p. 25-44) e Ehrlich (1971). 
As novas funções fazem com que o sistema político participe de modernos processos de conversão, ou seja, processos que transformam o fluxo de demandas e suporte do sistema político em um fluxo de extração, regulação e distribuição no contexto da sociedade.

\section{A articulação de interesses}

Quando falamos em articulação de interesses, refrimo-nos ao processo pelo qual indivíduos e grupos apresentam reivindicações aos responsáveis pela tomada de decisões políticas. Essa função é importante, já que sinaliza os limites entre a sociedade e o sistema político. Se os grupos que constituem a sociedade não encontram canais para expressar seus interesses e suas necessidades, é possível que suas demandas não sejam satisfeitas, propiciando que o sistema deixe de receber apoio e vá, assim, perdendo legitimidade.

Easton (1965, p. 116) definiu os grupos de pressão, assim como os partidos políticos, como "reguladores estruturais do volume de demandas", pois são os indivíduos que controlam a entrada de pedidos no sistema político. Esse controle se concretiza na redução do volume e da diversidade das solicitações, por meio da combinação de duas ou mais demandas em uma única demanda.

O processo de redução permite canalizar o fluxo de exigências, ordenando-as e reduzindo-as a um número limitado de alternativas, que são apresentadas aos gestores públicos. Pode-se, assim, tratar de reunir requerimentos semelhantes que foram apresentados de maneira dispersa. Entretanto, a redução não consiste unicamente na reunião e organização de exigências gerais, já que também reúne exigências específicas em uma demanda global. Os programas dos partidos ilustram este processo conjuntivo, reunindo uma combinação de exigências muito eclética, ordenadas em um todo mais ou menos coerente. Essa coesão se acentuou por meio da nova estrutura partidária com a aparição do catch-all party definido por Otto Kirchheimer.

A síntese e a homogeneização permitem simplificar e selecionar as múltiplas demandas ${ }^{7}$ para conseguir realizar uma ação dirigida e em consonância com os recursos do sistema. Essa regulação da conversão de necessidades sociais em exigências políticas se realiza por dois mecanismos: a regulação estrutural (o que pode converter uma necessidade em exigência) e a regulação cultural (qual necessidade pode ser socialmente aceita como demanda) ${ }^{8}$.

7 Richard Jankowski (1988, p. 195-225) define a agregação de preferências como uma função essencial no processo político da democracia, que varia segundo o tipo de organização política e das instituições do sistema.

8 Offe (1996) refere-se a instituições de controle social como aquelas instâncias encarregadas de regular a criação e a manutenção de normas de aspirações sociais e de valores culturais e políticos. 
Por meio da aplicação dessas normas endógenas e exógenas, todo sistema político pode responder, de forma total ou parcial, às reivindicações e demandas que cheguem a ele, vindos de dentro do ecossistema social.

A regulação estrutural da conversão das necessidades em exigências exige a noção de guardião e de barreira. O acesso ao sistema se concretiza mediante algumas barreiras estruturais, à frente das quais estão os guardiões. A função de guardião é uma função especializada na formulação e formação de exigências políticas: em um primeiro nível, estruturas muito específicas (associações sociais, sindicatos, sindicatos patronais) transmitem as exigências; em um segundo nível, os homens políticos e os partidos políticos têm a função de receber as necessidades e transformá-las em demandas políticas; e, em um terceiro nível, a withinput (autoalimentação do sistema político), as próprias autoridades convertem necessidades em exigências, seja para satisfazer a seus eleitores / cidadãos ou para melhorar sua própria imagem.

Já a regulação cultural permite enquadrar os pedidos como solicitações que se inserem no contexto cultural da sociedade. Toda demanda reconhece como a facilidade de acesso ao sistema político é inversamente proporcional ao distanciamento das pautas culturais. Um dos fatores essenciais à atividade do grupo consiste justamente em adequar seus pedidos à cultura política da sociedade na qual deseja atuar. R. Rose (1974, p. 269-271) estabeleceu uma taxonomia sobre as relações que podem se estabelecer entre um grupo de pressão e as pautas culturais de uma sociedade:

a) harmonia entre as demandas do grupo e as normas culturais gerais;

b) aumento gradual da aceitação dos valores políticos que apóiam as demandas do grupo de pressão;

c) negociações com o suporte flutuante por parte das normas culturais;

d) um trabalho de fomento frente a tendências culturais em mudança há muito tempo;

e) um trabalho de promoção ante a indiferença cultural;

f) um conflito entre os valores culturais e os objetivos do grupo.

\section{A agregação de interesses}

Os grupos de pressão, além da função de articulação de interesses, possuem uma função latente de integração, já que são sujeitos de socialização política, de canalização de reivindicações e de comunicação política entre os indivíduos e os governantes.

O fluxo comunicativo que se estabelece entre o sistema social e as instancias políticas foi definido por Meynaud (1962a, p. 116-118) como a ação realizada pelos grupos de pressão, que coletam a informação circulante na sociedade e a transmitem aos atores políticos. Desta forma, se integram as aspirações 
dos indivíduos que, sem essas organizações, não teriam canais formais, com exceção dos partidos políticos, com o consequente perigo de pedidos confusos e até mesmo violentos.

\section{A comunicação política}

Trata-se aqui da função de aceitação e de inserção das demandas realizadas na sociedade, assegurando assim a aceitação das decisões por parte dos interessados. Dessa forma, contribui-se para o consenso social e político.

Essas funções dos grupos no sistema político são uma ferramenta que contribui para reduzir as demandas sociais, a integrar as solicitações do sistema e a executar as decisões dos poderes públicos.

Todas as pretensões de estabelecer ilações entre grupos e gestores públicos têm o objetivo de reduzir as demandas sociais, com a intenção de reduzir ou eliminar a sobrecarga sistêmica. Entretanto, o sistema político não apenas desenvolve procedimentos redutivos, mas também realiza uma variante que, como visão antagônica, incide no aumento da capacidade produtiva estatal.

Nessa troca, o poder opera em dois níveis: de um ponto de vista, para a melhoria da eficiência administrativa, e, de outro, por meio da criação de canais formais de interação grupal e os gestores públicos.

O aspecto político repercute no aumento produtivo por meio da institucionalização de alianças e de mecanismos de cooperação entre instâncias decisórias e grupos de pressão. Essa situação tem feito com que, cada vez mais, haja uma colaboração entre poderes públicos e grupos. A colaboração ocorre em cada um dos países com diferentes especificidades e concretudes, que variam conforme os diferentes sistemas políticos ${ }^{9}$.

Essa cooperação pode adotar diversas opções, como a oficialização dos contatos entre órgãos governamentais e determinados grupos sociais (audiências, obrigação de ouvir as opiniões antes da decisão final etc.) e a constitucionalização, com o reconhecimento do seu papel e dos mecanismos de concorrência e regulamentação legislativa (um regulamento geral sobre os grupos de pressão como associações comuns - por meio de uma lei de associações - ou um regulamento específico para certos grupos - por exemplo, os conselhos profissionais).

Esteban (1967, p. 51-73) apresenta uma classificação da articulação e integração dos interesses no processo político:

9 P. C. Schmitter (1977, p. 7-38) estudou os mecanismos e as táticas utilizadas pelos grupos na intermediação de interesses. 
1. A representação extraparlamentar de interesses, que incluiria o exemplo da ação do lobistas nos Estados Unidos. Essa representação foi reconhecida pela primeira emenda da Constituição dos Estados Unidos, quando afirma que o Congreso "não restringirá o direito das pessoas de se reunir pacificamente e de dirigir petições ao Governo para reparação de injustiças". Essa orientação estaria refletida nos estágios iniciais da atividade dos grupos de pressão, até o momento em que sejam reconhecidos e regulamentados, de uma ou outra forma.

2. A quase-representação parlamentar de interesses, como são os partidos indiretos ou partidos de interesses econômicos (Loewenstein 1979, p. 433), que são organizações por meio das quais os grupos de pressão passam a participar no processo de elaboração das decisões do poder legislativo.

3. A representação intraparlamentar de interesses, materializada nos exemplos de determinados países que deixavam certa representação de interesses em alguma das câmaras. Um modelo extremo são as câmaras aristocráticas, nas quais estavam representados certos interesses minoritários do país.

4. A representação consultiva de interesses: os conselhos econômicos e outros órgãos consultivos. O primeiro conselho econômico data de 1880, quando o chanceler Otto von Bismark tentava reduzir o papel do parlamento, por meio da criação de uma nova câmara recrutada e constituída por interesses econômicos. Esses conselhos visam refletir, com a máxima fidelidade, a configuração social dos interesses diversos existentes em uma determinada sociedade. Após a Primeira Guerra Mundial, houve uma grande proliferação dessas instâncias. Assim, o primeiro conselho de tipo moderno apareceu na República de Weimar, com a pretensão de conter os defensores da república de conselhos, que haviam sofrido o impacto da Revolução Russa. Dessa forma, o art. 165 previa, como apoio do conselho econômico, uma série de conselhos de operários nas empresas e em nível regional. O fascismo contribuiu para desprestigiar a representação de interesses entre as classes operárias, situação essa que fez com que os Conselhos Econômicos unicamente aparecessem posteriormente na Constituição da França, de 1946, e na italiana, de 1947.

5. A representação empresarial de interesses específicos na realização de negociações diretas entre os grupos e as autoridades públicas. Distancia-se dos canais formais e institucionais, ou seja, de todas as atividades institucionais, incluindo os acordos entre o governo e um grupo de pressão. Quanto ao âmbito da discussão na negociação, não é necessário ou essencial que ele tenha uma dimensão setorial, mas o seu alcance pode ser para toda a comunidade.

6. A representação parlamentar de interesses, com a criação de assembleias econômicas. Aparece como um sistema misto de representação, no que 
se diferencia entre uma representação geral ou política e uma representação de interesses particulares.

\section{FORMAS E MODO DE ATUAÇÃO DOS GRUPOS DE PRESSÃO}

Uma das características estruturais do sistema político é o fato de que, há algum tempo, já não se pode dizer que o canal representativo-democrático seja o único, ainda que seja o mais importante, para elaboração, criação e implementação de políticas públicas. Reduzir exclusivamente as formações e formulações de petições a canais formais e explícitos seria defender uma visão completamente alheia a uma realidade, ao não poder esta ignorar os inputs sociais provenientes de entidades associativas que visam influenciar o governo ${ }^{10}$.

A eficácia dos grupos de pressão ${ }^{11}$ é determinada por numerosos fatores. Dentre eles, destacam-se: a capacidade para mobilizar os seus membros, a energia e os recursos disponíveis; a posição e a imagem do grupo perante a sociedade; a eficiência de sua organização interna; a possibilidade de acesso aos gestores públicos e/ou parlamentares; e a adequação de seus interesses aos valores determinantes da sociedade.

Antes de iniciar qualquer tipo de atividade, os grupos devem ter clara a sua posição em relação aos poderes decisórios. Normalmente, ocorrem três possíveis situações:

a) uma disposição passiva que parte da observação da elaboração das decisões, limitando a atividade ao momento da decisão final. Essa tendência é claramente negativa, já que não permite introduzir as propostas do grupo no processo criador das decisões públicas;

b) realizar um trabalho ativo na preparação das propostas quando se está no processo de consultas. Os grupos que estão nessa situação têm a vantagem de causar impacto sobre as propostas e de poder influenciar na decisão final;

c) vocação aprioristica que permite identificar as decisões e ações futuras para, dessa maneira, se estar prevenido e, consequentemente, ter a capacidade de minimizar os inconvenientes e maximizar as vantagens. Essa é a melhor atuação que um grupo pode adotar, pois permite lutar contra o surgimento de aspectos negativos para ele e, ao mesmo tempo, estabelece a possibilidade de propor as próprias propostas e não ir a reboque de outras iniciativas.

10 Esta atuação dos grupos sociais foi agrupada por M. Kalecki (1971) como business confidence.

11 As fontes do poder político, a organização dos grupos de pressão, os esforços dos grupos para mobilizar ações dos governantes e a resposta dos políticos tem sido descritas por diversos autores, tais como: Buchanan e Tullock (1962); Peltzman (1976, p. 211-240); Bacheller (1977); e Ehrlich (1963, p. 25-43). 
Para poder influenciar convenientemente, devem-se utilizar técnicas de intervenção com a pretensão de modificar, de alguma maneira, as decisões das autoridades, em um sentido favorável às suas reivindicações materiais ou morais. Essas técnicas são a negociação e a argumentação, a mobilização dos adeptos, a utilização do dinheiro e a aplicação de todos os mecanismos legais que sejam permitidos.

O efeito de uma mensagem depende tanto do emissor como do receptor. Este é de grande importância, porque a comunicação muitas vezes transmite uma mensagem não solicitada. Essa idiossincrasia se faz necessária para conquistar a atenção do destinatário. Uma técnica que não para de crescer é a da persuasão, que trata de convencer, por meio da exposição de argumentos racionais ou que parecem ser. Os recursos econômicos são fundamentais, pois nos permitem melhorar qualitativa e quantitativamente a natureza da mensagem. Para Michel Le Net (1968, p. 61), no processo de persuasão existem três fatores:

a) A atenção do destinatário que exerce um papel de filtro, controlando a natureza e qualidade da informação recebida. O filtro tem como funções principais: (i) proteger o individuo contra o volume exagerado de informações que torna impossível uma assimilação total; e (ii) selecionar a informação mais interessante pela qualidade de enriquecimento ou de teste. Para influenciar, a atenção deve ser mantida pela mídia-alvo como condição para poder impactar.

b) A compreensão é básica, já que uma mensagem não entendida é uma mensagem não recebida.

c) A aceitação da mensagem é a precondição da mudança de atitude.

\section{Negociações e a argumentação}

As negociações e a argumentação compreendem a troca de opinião de qualquer natureza que possa ocorrer entre as autoridades oficiais e os grupos de pressão em relação a uma questão específica. Assim, essas conversas integram as oficiais, oficiosas, secretas, públicas, solenes, latentes, manifestas. Toda consulta se realiza em dois momentos: na fase da elaboração do projeto ou texto; e, uma vez que esteja finalizado, em sua aplicação (toda lei necessita do desenvolvimento de um regulamento). Aos grupos de pressão interessa participar na gestação do projeto para envolver-se, desde o principio, no processo de criação e assim poder introduzir o maior número de apreciações próprias no texto.

A atuação deve ser ativa e mutável em relação ao sistema político no qual está inserida. Não existe um principio nem um final sobre a ação, já que se deve estar em um estado de alerta permanente, atuando sobre diversos lugares ao mesmo tempo.

As etapas de atuação são permanentes, não existindo um inicio e tampouco uma finalização. Assim, o grupo entra em um circuito que se vai retroalimen- 
tando de cada uma das respostas recebidas. Esse jogo implica um conjunto de interrelações entre os grupos e outros atores do sistema social em permanente movimento (veja figura 1).

Figura 1 - Processo do lobbying

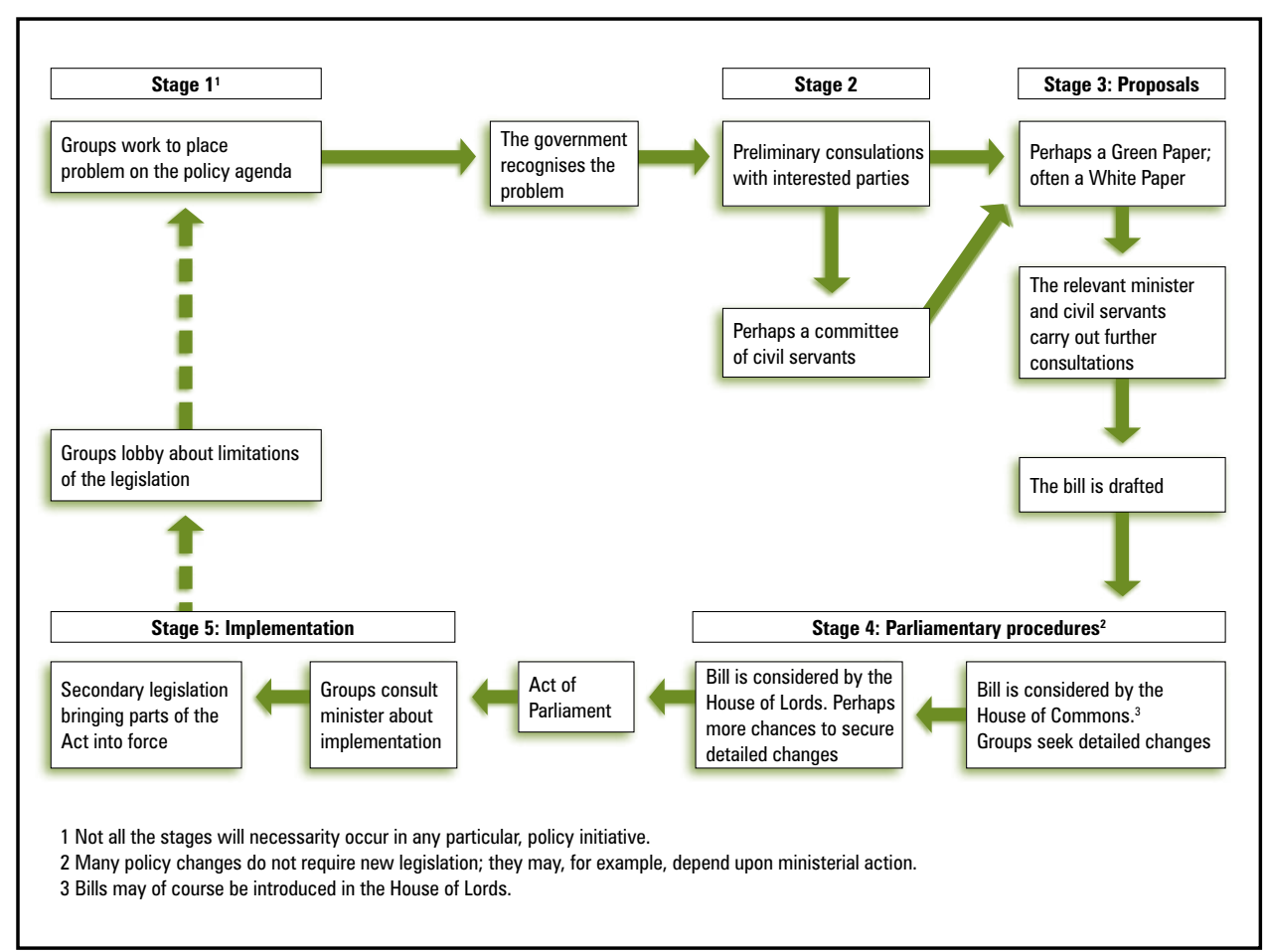

Fonte: Grant, 1989, p. 49

Em sua ação, nem todos os grupos podem penetrar de forma fácil nesse sistema, já que se deve conquistar uma imagem de forma prévia, percepção que lhe permitirá aparecer como grupo suscetível de entrar no sistema. Para poder ser chamado à formação da política, é necessário que os antecedentes do grupo sejam a seriedade e a formalidade em outros momentos, aspecto que possibilita uma boa representação pública.

Um exemplo é a técnica utilizada por empresários japoneses com a intenção de criar uma boa imagem pública. A Câmara de Comércio e de Indústria de Osaka manteve durante dez anos (1981-1990) o programa Tyop (Ten Young Outs Tanding Persons). Este consistiu no convite a dez jovens bem selecionados, provenientes de dez países do mundo, para visitar o Japão, a cada outono. Cada uma dessas pessoas representava uma categoria profissional determinada: em um ano, os candidatos eram escolhidos dentre jovens da política e, nos anos posteriores, de outros campos sociais (economia, cultura etc.). A inten- 
ção do programa era bem clara: desenvolver a compreensão mútua no mundo, gerando oportunidades de comunicação entre os países. Mas, subrepticiamente, aparece a intenção de: estabelecer uma agenda de contatos de pessoas que no futuro ocuparão posições sociais significativas; difundir uma imagem positiva de seu país a pessoas-chave do ponto de vista social; e criar e conservar relações fiéis e frutíferas.

Uma excelente ideia consiste em elaborar e remeter às autoridades responsáveis uma documentação sobre a temática. Esse documento não deve ser dirigido apenas aos altos dirigentes, mas também aos funcionários. Deve expressar a ótica favorável aos interesses do grupo, mas sem expressar qualquer tipo de mentira ou inexatidão. Uma apresentação hábil e adequada torna difícil descobrir a orientação dos argumentos utilizados, pelo que, para o interlocutor, se apresenta como uma tarefa árdua averiguar aquelas seções em que se passa dos fatos objetivamente verdadeiros para juízos ou posições interessadas.

\section{Mobilização dos adeptos}

É preciso mobilizar adeptos para realizar demonstrações públicas da força numérica (apesar de a adoção de criar conscientemente um mal-estar social poder ter repercussões negativas para a imagem grupal). Essa ação tenta envolver os cidadãos na realização de finalidades, como poderia ser o exemplo da Common Cause. Esta organização foi criada, em 1970, por John Gardner, um homem de múltiplos campos de ação - presidente da Foundation Carnegie, autor de dois best-sellers (Excellence, 1961; e Self-renewal, 1963), secretário de Estado da Saude, da Educação e do Bem-estar Social (1965-1968) e presidente de duas comissões de política educativa. A Common Cause tem como objetivo exercer pressão a favor da vigilância do financiamento público das eleições presidenciais, da regulamentação sobre as atividades dos grupos de pressão (essa ação foi definida como lobby contra os lobbies) e da descoberta de receitas não-governamentais dos congressistas e altos funcionários.

A mobilização dos cidadãos e simpatizantes pode ser exclusiva (de maneira constante $^{12}$ ) ou valer-se de uma ou mais técnicas e recursos do conjunto de instrumentos colocados ao alcance do grupo. Normalmente, as chamadas para realizar atos com base na intimidação pela força numérica dos indivíduos participantes fazem parte das estratégias daqueles grupos de pressão dos quais participa um número de pessoas muito sensibilizadas na questão ou pela grande quantidade de membros do grupo. Além disso, as ações pretendem incidir sobre aquelas posições estratégicas para a evolução normal da vida social, buscando a maior e mais ampla repercussão social.

12 Esse tipo de grupos se situa no modelo contestatório, que Frank Wilson (1983, p. 220-254) comparou com os modelos pluralista e corporativista em relação às atividades dos grupos de pressão. 
Quando a intenção exclusiva consiste em uma mobilização dos indivíduos, Carlos Fayt (1985) define as associações como grupos de tensão, em relação às organizações que tentam conseguir mudanças em outros atores, singularmente, pela via violenta. Para Fayt (1945, p. 341-345), o aparecimento ou a criação desse tipo de grupo necessita de uma serie de requisitos, como no caso de a defesa dos interesses exceder o contexto da petição ou pretensão, seja pela insuficiente da demanda pública ou pela natureza dos interesses defendidos ou pela negativa dos órgãos públicos em satisfazer tais demandas. O surgimento desse tipo de associações está imbricado por múltiplos fatores, tais como a teleologia grupal, a forma de organização e meios de ação e a correspondência com sua posição no quadro social, na ordem econômico e na classe efetivamente no domínio do poder político. Nesse sentido, as características que essa taxonomia de grupos tem implicam um grande número de situações pessoais e sociais. Os grupos:

a) têm a autoconsideração de estarem aprisionados pela legalidade formal, submetidos à insegurança material, em luta por melhores condições de vida e de estarem resistindo a uma ordem social que se considera injusta;

b) criam e provocam anormalidade formal e, em ocasiões, anormalidade material, à margem da legalidade;

c) vão contra o poder político e o poder social, vindo sua força basicamente do número de representantes, uma força mais quantitativa que qualitativa;

d) tentam desarticular a ordem pública, sem constrangimentos quanto à convulsão social nem à anarquia, não buscando conservar, mas melhorar suas condições sociais;

e) se confrontam com o poder, excluindo toda possibilidade de suborno ou corrupção;

f) o grande número de membros e a solidariedade de grupos afins lhes proporciona a força social necessária para suas ações, que podem ir do estado de alarme até a greve;

g) carecem de potencial econômico suficiente para poder utilizar amplamente os meios de comunicação.

h) mobilizam grandes setores sociais e produzem deliberadamente estados de tensão por meio da paralisação das atividades sociais, aproveitando-se assim da interdependência que existe na atualidade.

A existência de grupos de tensão puros, isto é, que realizam unicamente a ação violenta, é mínima na sociedade, já que, se for significativa, pode levar a graves conflitos e, até mesmo, à mudança do sistema político. Para a mobilização da opinião pública existem numerosos métodos entre os quais podemos citar: 
- atuação violenta e direta como manifestações públicas, desfiles, dar mercadorias, greves ${ }^{13}$;

- intervenção violenta e indireta, como não pagar impostos, desobediência civil, não ajudar os poderes públicos na aplicação ldas leis;

- ação pacífica para chamar a atenção sobre determinadas questões, a fim de conseguir que passem à agenda da discussão pública e, em consequência, se tornem suscetíveis de serem solucionados; dentro desse tipo de intervenção, aparecem novas formas de acesso aos gestores públicos, como é o caso do chamado grassroots lobbying (enviar cartas, telegramas, chamadas telefônicas, uso de redes sociais...) aos poderes públicos e aos meios de comunicação ${ }^{14}$.

Com essa técnica, os grupos de pressão desejam conseguir que pareçam naturais e espontâneas as notificações a favor de uma determinada ação. Se a pessoa que deve tomar uma decisão começa a receber todo tipo de mensagens de pessoas individuais que, em teoria, as enviam de forma anônima, parecerá que uma importante quantidade de sujeitos demanda uma determinada posição. Para realizar o grassroots lobbying de maneira mais efetiva, são fundamentais duas características:

- que a ação pareça ser espontânea, isto é, o receptor dessa atividade não deve pensar que forma parte de uma campanha organizada;

- que as demandas sejam coerentes com o objetivo demandado, já que apresentar propostas que não sejam pertinentes pode levar ao rechaço.

Essas peculiaridades levaram à criação de manuais de atuação para dar indicações de como agir, como no exemplo de um opúsculo da Common Cause, de 22 páginas, enviado a seus membros (McFarland, 1987a, p. 197), no qual se aconselhava:

Em primeiro lugar, você deve se familiarizar com as questões listadas aqui (existe uma relação das prioridades reformistas do grupo).

Em segundo lugar, escreva uma carta a cada candidato de sua região, expressando com suas próprias palavras por que esses pontos para um governo aberto e responsável são importantes para você como eleitor. Os nomes e o endereço dos candidatos de seu estado estão anexados a esse relatório. Por favor, escreva as cartas imediatamente. Elas despertarão o interesse dos candidatos e os farão

13 Chabanol e Meynaud (1962, p. 27-38) estudaram o comportamento dos grupos de pressão em situações nas quais suas demandas e reivindicações iniciais não têm eco no poder público. Para estudar as estratégias e o impacto social dos movimentos de protesto, ver também Kitschelt (1986, p. 57-85).

14 Essa técnica é um tema muito estudado na ciência política norte-americana, sobretudo à margem da aparição do chamado new lobbying. Exemplo do estudo de grassroots é o trabalho de Loomis (1987, p. 169-190). Também, Fowler e Shaiko (1987, p. 484-510) ressaltam que essa técnica experimentou um aumento considerável nos últimos anos. 
pensar sobre as propostas. Você não necessita fazer perguntas aos candidatos aos quais escreve, pois eles estão ocupados com a campanha política e possuem pouco tempo para responder às cartas. Os olhos e ouvidos do candidato estão abertos aos problemas que preocupam o eleitorado e as cartas são um bom meio para chamar a sua atenção. A correspondência pode influir nos temas sobre os quais os candidatos falam e nas promessas que fazem aos eleitores.

Em terceiro lugar, promova esses temas com cartas aos editores de jornais locais, rádios e semanários que não cobrem assuntos políticos em profundidade.

Em quarto lugar, quando você assiste reuniões com os candidatos ou é transmitido um programa de perguntas, explicite as propostas da Common Cause e peça respostas. As "perguntas que você pode fazer aparecem ao final de cada capítulo deste relatório”.

Como podemos verificar, as instruções e recomendações são exaustivas para os membros e simpatizantes do grupo, já que esse briefing permite destacar as questões que mais interessam à associação e ajuda as pessoas que não sabem como e nem a quem fazer perguntas.

Por outro lado, o uso do potencial da rede pressupõe uma melhora dos fluxos de demandas sobre os poderes públicos e sobre os meios de comunicação. Assim as campanhas na internet buscam mais facilmente reunir o apoio de pessoas geograficamente dispersas e realizar atividades específicas de lobby através dos cyberativistas.

\section{Utilização do poder financeiro}

O fundador da Common Cause expressou que o maior perigo da concentração do poder econômico consistia na crescente capacidade de influenciar no sistema público por meio do dinheiro. Nesse sentido, isso pode ser traduzido em facilidade de acesso, como é o caso de Harold Geneen, que, por meio do financiamento da Convenção Nacional Republicana, não teve nenhum problema para discutir assuntos de antitruste com o presidente do Conselho da Reserva Nacional. Sobre essa ação, Gardner afirma: "isso é acesso. E qualquer cidadão comum que tente estabelecer um programa similar de reuniões aprenderá tudo o que faz falta saber sobre a influencia do dinheiro na política” (McFarland 1987a, p. 251).

O dinheiro desempenha um papel no desenvolvimento e na implementação de todas as atividades do grupo, desde uma greve até a preparação de certa documentação. O pecúlio pode ser utilizado para obter favores e a cumplicidade dos homens e dos partidos políticos, seja de uma forma aberta ou subreptícia. Mas também pode financiar abertamente as campanhas eleito- 
rais dos candidatos e partidos. A essa função se acrescenta o chamado new lobby $^{15}$, com uma função de informação, de educação da opinião pública para tentar influenciá-la em uma direção e sempre de acordo com os objetivos dos grupos de pressão.

Um exemplo de como o pecúlio pode ser utilizado para obter favores e cumplicidade é o caso de dois altos funcionários do governo britânico, os deputados Tim Smith e Neil Hamilton que cobravam 2 mil libras esterlinas cada vez que formulavam, na Câmara dos Comuns, perguntas favoráveis aos interesses do magnata egípcio Mohammed Al Fayed. Além disso, Hamilton desfrutou de uma viagem, com sua esposa, a Paris com todos os gastos pagos no hotel Ritz ${ }^{16}$.

Os japoneses são mestres na utilização honesta dos pecúlios para neutralizar as críticas contra eles. O método que se utiliza é o seguinte: oferecer a um homem político, que em principio é hostil a seus interesses, a possibilidade de viajar ao Japão para conhecer as realidades do país. Essa viagem se encontra enquadrada em um ciclo de conferencias, pagas com 5 mil dólares para uma personalidade de interesse médio e mais de 40 mil para uma alta personalidade. A inicial hostilidade, frequentemente, tende a diminuir no seu regresso ${ }^{17}$.

\section{Uma visão abrangente das formas de atuação}

Todas essas formas de ação não são fechadas em si mesmas, pois podem ocorrer simultaneamente em diferentes áreas. No caso da Common Cause, existe a coordenação do conteúdo e ritmo das mensagens ao poder legislativo, provenientes dos lobistas do grupo, a realização do grassroots sobre os gestores públicos, assim como a prática de pleitos nos tribunais (McFarland 1987a). Deve-se exercer pressão simultaneamente sobre os gestores públicos e naquelas diligencias que incidem no público. Daí ser essencial dirigir-se adequadamente aos membros da associação, para informar-lhes sobre onde, quem, quando e o que escrever.

Uma ideia básica na realização da pressão é possuir todo tipo de informação que permita assegurar que os meios certos chegam às pessoas adequadas no momento oportuno. Além disso, a arte da pressão deve se moldar àqueles mecanismos que permitam a participação na organização política na qual se está inserido, mudando suas técnicas sincronicamente de acordo com a mutação do sistema organizativo. Assim, toda mobilização de um grupo de pressão deve ter uma serie de etapas a cumprir, se o desejo for atuar da melhor maneira possível:

15 Whiteley e. Winyard (1984, p. 32-54) estudaram essa nova concepção do lobby.

16 informação retirada de La Vanguardia, 26 out. 1994.

17 Sobre esta tática de influência, ver Choate (1990). 
1. Definir os objetivos de forma clara, para poder distribuir os recursos disponíveis. Segundo características próprias de cada grupo, essa atuação será mais ou menos fácil, já que os grupos que buscam objetivos específicos possuem mais facilidade do que as associações que defendem interesses heterogêneos.

2. Selecionar as temáticas que serão objeto de monitoramento, análise e intervenção. Una premissa para essa etapa é a informação previa que o grupo possua sobre os assuntos que devem ser realizados no futuro. Contudo, não é necessário intervir unicamente com iniciativas exógenas, mas há que se estabelecer uma hierarquia e um modo de atuação endógeno para seus interesses.

3. Identificar os campos e os sujeitos sobre os quais se pretende exercer influência. Deve-se ter claro o tempus para se poder proceder no momento adequado. Basicamente se farão as intervenções:

a) no interior dos poderes públicos. A ação será diferente de acordo com o perfil dos interlocutores, não podendo os argumentos se contradizer com o passar do tempo e devendo adequar-se aos sujeitos e aos lugares sobre os quais se incide. As propostas devem ter consistência, para não intimidar os adversários, pelo menos no primeiro momento da ação, pois uma mudança de orientação muito drástica de um assunto terá repercussão na credibilidade que o público tenha sobre ele;

b) por meio da opinião pública como instrumento indireto de pressão sobre os gestores públicos e/ou parlamentares.

4. Selecionar as técnicas mais adequadas a cada situação. As mais importantes são:

a) ação direta sobre os assuntos, por meio de comunicados pessoais, apresentações, contatos, reuniões formais e informais, briefings, cartas, conversas por telefone;

b) ação indireta, com a criação de campanhas de cartas, campanhas de relações públicas (discursos, artigos, campanhas de imprensa, opiniões de líderes sociais) e utilização dos procedimentos legais e jurídicos;

c) utilização do poder financeiro com a contribuição nas campanhas políticas de partidos e candidatos por meio de dinheiro ou de serviços;

d) organização de coalizões com a coordenação dos interesses de outras organizações para poder atuar com maior força.

Em sequência a essas técnicas e, uma vez que as ações legais tenham sido esgotadas, pode-se realizar uma série de práticas eticamente duvidosas, mas que podem ajudar a alcançar a finalidade: 
- distorcer fatos, emitir mensagens dissimuladoras, obstruir informação, distorcer eventos, utiliza métodos de intimidação e ataques pessoais, desacreditar adversários;

- fazer cooptação para neutralizar ou pôr em dúvida os partidários da parte contrária, com postos de trabalho, honorários excessivos, presentes etc.;

- retardar a implementação de procedimentos, usando técnicas obstrucionistas.

5. Uma vez que se tenha finalizado a operação, começa a parte analítica, com o controle e a avaliação de tudo o que se realizou e o resultado alcançado. Toda ação de um grupo é um processo contínuo que não finaliza nunca, já que a situação social é muito mutável e sempre é preciso adequar as atividades e técnicas à perspectiva social do momento.

Essas atividades são aplicadas em qualquer poder da sociedade, mas na realidade, se destacam no executivo, no legislativo, no judiciário, nos partidos políticos e na opinião pública. Devido à diversificação estrutural de diferentes sistemas políticos, nos quais a distribuição de poder está dividida em modos diferentes, cada grupo deve adequar suas ações naquelas posições considerados mais relevantes ou favoráveis aos seus interesses. Quando grupos de pressão procuram proteger e promover os interesses que representam, por meio de instrumentos políticos, devem, em primeiro lugar, modelar sua organização à estrutura política sobre a qual querem influenciar e, em segundo lugar, garantir uma posição estratégica diante dos diferentes centros de decisão política.

As estratégias são inúmeras e devem estar inter-relacionadas para se alcançar um alto grau de objetivos. Simultaneamente, deve-se atuar em muitas esferas, onde as ações dos grupos são numerosas e abarcam todo tipo de pessoas e de organizaçõe. Não se deve deixar de influenciar nenhuma atividade ou instituição significativa, sendo, por isso, de extrema importância estabelecer um órgão coordenador que permita intervir no lugar certo e no momento mais preciso.

\section{CONSIDERAÇÕES FINAIS}

Em um sistema democrático, influenciar a opinião pública é fazê-lo indiretamente sobre o poder político. Todo poder adiciona um grau de dificuldade em sua atividade quando as medidas que pretende adotar contam com uma opinião pública desfavorável. Conhecedores dessa situação, os grupos de pressão realizam ações sobre o público, como um ensaio persuasivo para desenvolver o recrutamento ou criar uma atmosfera de simpatia e compreensão geral de suas demandas e aspirações

O jogo político se organiza e se estrutura sobre a opinião pública em seu aspecto moderno e a luta política tende a se transformar, cada vez mais, em uma batalha para conquistar a opinião. O essencial da dominação política reside no mecanismo fundamental de ordem simbólica. A ação política mais importante 
se apresenta de modo sorrateiro e subrepticio, ao consistir, sobretudo, na imposição de sistemas de classificação do mundo social.

Nessa luta simbólica, cada ator busca e pretende monopolizar e fazer triunfar sua singular visão da ordem social e impô-la como justa e verdadeira ao maior número de indivíduos. Procurar mudar essas percepções torna imprescindível contar com os meios de comunicação, que são os que relacionam, principalmente, os grupos com o conjunto da sociedade e difundem suas aspirações e reflexões.

O principal problema dessa pluralidade de opiniões entre os indivíduos provém da limitação discursiva de nossa sociedade, a qual postula uma hierarquização das opiniões que nela circulam. Assim, ao mesmo tempo em que determinados discursos se mostram privilegiados, outros se veem afastados e silenciados, diante da possibilidade de se ter acesso privilegiado aos meios de comunicação. Assim, os indivíduos ou as instituições sociais que desenvolvem estratégias discursivas mais poderosas conseguem apresentar uma imagem daquilo que a opinião pública deseja, quando, na realidade, o êxito será de uma dessas opiniões.

\section{REFERÊNCIAS}

ALMOND, Gabriel A.; POWELL Jr, G. Bingham. Política comparada. Buenos Aires: Paidós, 1972.

BACHELLER, John M. Lobbyists and the legislative process: the impact of environmental constraints. The American Political Science Review, v. LXXI, n.1, mar. 1977.

BENTLEY, Arthur F. The process of government: a study of social pressures. Chicago: Chicago University Press, 1908. Il processo di governo: uno studio delle pressione sociali. Trad. de Giusepp Buttà, Milano: Giuffrè, 1983.

BERRY, Jeffrey. Lobbying for the people: the political behavior of public interest groups. Princeton: Princeton University Press, 1977. The interest group society. Glenview, IL: Scolt Foresman / Little, 1989.

BUCHANAN, James McGill; TULLOCK. Gordon. The calculus of consent: logical foundations of constitutional democracy. Ann Arbor, MI: University of Michigan Press, 1962.

BURDEAU, Georges. Traité de science politique. Tome III - La dynamique politique, Vol. I - Les forces politiques. Paris: Librairie Génerale de Droit et Jurisprudence, 1982.

CAMPS, Victòria; GINER, Salvador. El interés común. Madrid: Centro de Estudios Constitucionales, 1992.

CASTILLO, Antonio. Grups de pressió i mitjans de comunicació: anàlisi de I'ùs dels mitjans comunicatius per promoure interessos associatius. Tesis (Doctorado) - Universitat Autònoma de Barcelona. Barcelona, 1997.

CAZZOLA Franco. Política, intereses y reducción de los recursos: consideraciones sobre el caso italiano. Revista de Estudios Políticos, n. 40, p. 25-44, jul.-ago. 1984.

CHABANOL, Daniel; MEYNAUD, Jean, Comportament des groupes dans les situations d'echec, Revue Française de Science Politique, v. XII, n. 1, p. 27-38, mar. 1962.

CHOATE, Pat Agents of influence: how Japan's lobbyists in the United States manipulate America's political and economic system. New York: Knopf, 1990.

DION, León. Los grupos y el poder político en los Estados Unidos. México: Grijalbo, 1967.

Société et politique: la vie des groupes. Vol. I - Fondements de la société. Vol. II -Dynamique de la société libérale. Québec: Les Presses de I'Université Laval, 1982.

84 NOVOS CENÁRIOS DE PARTICIPAÇÃo POLÍTICA: ANÁLISE DAS ESTRATÉGIAS DE COMUNICAÇÃO DOS GRUPOS DE PRESSÃo (LOBBIES) - ANTONIO CASTILLO ESPARCIA 
EASTON, David. Esquema para el análisis político,. Buenos Aires: Amorrortu Editores, 1965.

Enfoques sobre teoría política. Buenos Aires: Amorrortu Editores, 1982.

EHRLICH Stanislaw. Le pouvoir et les groupes de pression. Paris: Mouton, 1971.

. Les groupes de pression et la structure politique du capitalisme. Revue Française de Science Politique, v. XIII, n. 1, p. 25-43. mar. 1963.

ESTEBAN, Jorge de. La representación de intereses y su institucionalización: los diferentes modelos existentes. Revista de Estudios Políticos, n. 155, p. 43-74, sept.-oct. 1967.

FARNEL, Frank J. Le lobbying: strategies et techniques d'intervention. Paris: Les Éditions d'Organisation, 1994.

FAYT, Carlos S. Derecho político. Tome II. Buenos Aires: Ediciones de Palma, 1985.

FINER, Samuel E. Anonymous empire: a study of the lobby in Great Britain. London: Pall Mall Press, 1958.

FOWLER, Linda L.; SHAIKO, Ronald G. The grassroots connection: environmental activists and senate roll calls. American Journal of Political Science, v. 31, n. 3, p. 484-510, ago. 1987.

GARCIA PELAYO, Manuel. Las transformaciones del estado contemporáneo. Madrid: Alianza Editorial, 1994.

GARDNER, John. Excellence. New York: Harper \& Row, 1961. Self-renewal. New York: Harper \& Row, 1963.

GINER, Salvador; PÉREZ YRUELA, Manuel. La sociedad corporativa. Madrid:.CIS, 1979. El corporativismo en España. Barcelona:Ariel, 1988.

GRANT, Wyn. Pressure groups, politics and democracy in Great Britain. New York: Philip Allan, 1989.

HALE, Myron 0. The cosmology of Arthur F. Bentley. American Political Science Review, n. 54, p. 955-961, 1960.

JANKOWSKI, Richard. Preference aggregation in political parties and interest groups: a synthesis of corporatist and encompassing organization theory. American Journal of Political Science, v. 32, n. 1, p. 195-125, febr. 1988.

KAISER, Joseph H.: Die Repräsentation organisierter Interessen. Berlin: Duncker \& Humblot 1956.

KALECKI, Michal. Selected essays on the dynamics of capitalist economy - 1933-1970. Cambridge: Cambridge University Press, 1971.

KING, Anthony (Ed.). The New American political system. 2. ed. Washington: The American Enterprise Institute, 1990.

KITSCHELT, Herbert. Political opportunity structures and political protest: anti-nuclear movements in four democracies. British Journal of Political Science, v. 16, n. 1, p. 57-85, Jan. 1986.

LE NET, Michel, La communication sociale. In: Collection Notes et Études - La documentation française, Paris, n. 4866, 1988.

LOEWENSTEIN, Karl. Teoría de la constitución. Barcelona: Ariel, 1979.

LOOMIS, Burdett A. A new era: groups and the grassroots. In: CIGLERAND, Allan J.; LOOMIS Burdett A. (Ed.). Interest group politics. Washington, DC: CO Press, 1987. p. 169-90.

McFARLAND, Andrew S. Los grupos de presión en el Congreso norteamericano. México: Gernika, 1987a.

. Interest groups and theories of power in America. British Journal of Political Science, v. 17, n. 2, p. 129-147, abr. 1987b.

MENCKEN, Henry Louis. The American language: an inquiry into the development of English in the United States. New York: A. A. Knopf, 1919.

MEYNAUD, Jean. Nouvelles études sur les groupes de pression en France. Paris: Armand Colin, 1962a. . Los grupos de presión. Buenos Aires: Eudeba, 1962b.

. Les groupes patronaux et I'opinion. II Politico - Rivista di Scienze Politiche, a. XXXI, n. 3, p. 413-437, 1966.

. Les groupes de pression en France. Paris A. Colin, 1958.

MEYNAUD, Jean; SIDJANSKI, Dusan. Les groupes de pression dans la Communauté Européenne- 1958-1968 Bruxelles: Institut de Sociologie, 1971.

MEYNAUD Jean; MEYRIAT, Jean. Les groupes de pression en Europe occidentale: état des travaux. Revue Française de Science Politique, a. 9, n. 1, p. 229-246, 1959.

MURILLO FERROL, Francisco. Estudios de sociología política Madrid: Tecnos, 1963.

NÚÑEZ ENCABO, Manuel. La ambivalencia de los medios de comunicación: poderes y contrapoderes. In: TEZANOS, José Fèlix (Ed.). La democracia post-liberal. Madrid: Ed. Sistema, 1996. p. 215-236. 
ODEGARD, Peter H. Pressure politics: the story of the Anti-saloon League. Columbia, Columbia University Press, 1928.

OFFE, Claus. Partidos políticos y nuevos movimientos sociales. Madrid: Sistema, 1996.

PEACOCK, Alan. Elección pública: una perspectiva histórica. Madrid: Alianza Editorial, 1995.

PELTZMAN. S. Toward a more general theory of regulation. Journal of Law and Economics, n. 19, p. 211-240, 1976.

POTTER, Allen M. Organized groups in British national politics. London: Faber and Faber, 1961.

ROSE, Richard. Politics in England. Boston: Little Brown \& Company, 1974.

SALISBURY, Robert H. The paradox of interest groups in Washington - More groups, less clout. In: KING Anthony (Ed.). The new American political system. 2. ed. Washington, DC: American Enterprise Institute, 1990. p. 203-229.

SCHMITTER, Philippe. C. Modes of interest intermediation and models of social change in Western Europe. Comparative Political Studies, v. 10, n. 1, p. 7-38.1977.

SCHUBERT, Glendon. The public interest: a critique of the theory of a political concept. Glencoe: Free Press, 1960.

SORAUF, Frank J.; BECK, Paul Allen. Party politics in America. Illinois: Scott, Foresman and Company, 1987.

STEWART, Joseph D: British pressure groups. Oxford: Clarendon Press, 1958.

STREEK Wolfgang; SCHMITTER, Philippe C. (Ed.). Private interest government. London: Sage Publications, 1985.

TAYLOR, Robert W. Arthur F. Bentley's political science. Western Political Quarterly, n. 5, p. 214-230, 1952.

TOCQUEVILLE, Alexis de. La democracia en América. Vol. I e II. Madrid: Alianza Editorial, 1980.

TRUMAN, David B. The governmental process, political interest and public opinion. New York: Alfred A. Knopf, 1968.

WARD, James. Arthur Bentley's philosophy of social science. American Journal of Political Science, v. 22, n. 3, p. 595-603, ago.1978.

WILSON, Frank. Les groupes d'intérêts sous la cinquième republique: test de trois modèles théoriques de I'intéraction entre groupes et governement. Revue Française de Science Politique, v. 33, n. 2, p. 220-254, abr. 1983.

WILSON, Graham K. French interest groups politics: pluralist or neocorporatist? The American Political Science Review, v. 77, n. 4, p. 895-910, Dec. 1983.

WHITELEY, Paul F.; WINYARD, Stephen J. The origins of the new poverty lobby. Political Studies, v. XXXII, n. 1, p. 32-54, mar.1984.

WITTENBERG, Ernest; WITTENBERG, Elisabeth. How to win in Washington: very practical advice about lobbying, the grassroots and the media. Oxford: Basil Blackwell Publishers, 1989.

Recebido em: 22.06.2011 / Aceito em: 22.07.2011

86 NOVOS CENÁRIOS DE PARTICIPAÇÃO POLíTICA: ANÁLISE DAS ESTRATÉGIAS DE COMUNICAÇÃO DOS GRUPOS DE PRESSÃO (LOBBIES) - ANTONIO CASTILlO ESPARCIA 